\title{
SOME SOCIAL ASPECTS OF THE MEDICAL MALPRACTICE DILEIVIMA
}

\section{DAVID MECHANIC*}

Current medical malpractice problems are symptomatic of deeper issues in the practice of medicine, in our system of social insurance, and in the fabric of our society. The noisy manifestations of the malpractice debate-complaints about staggering increases in the insurance premiums physicians pay in certain vulnerable specialties ${ }^{1}$ or about contingent fees of attorneys ${ }^{2}$ - are perhaps some of the least important aspects. As is true of many other problems, the symptoms are more easily treated than the basic malady, but symptomatic treatment at best buys time to examine, to reflect, and to consider more basic long-term approaches.

A great deal has been written about malpractice, but pertinent data to answer many obvious questions are not readily available. Thus, it becomes difficult to distinguish the speculative but plausible hypothesis froin the true state of affairs. This Article can do little to remedy this basic shortcoming, smce I have no new data to clarify issues where they have becoine obfuscated. My objectives, however, are to define the basic issues underlying the inalpractice dilemma, to clarify some common concepts that are amenable to research, and to suggest certain hypotheses that deserve examination.

Medical inalpractice litigation is said to perform two important functions: (1) to deter pliysicians from lax, careless, or negligent behavior; $;$ and (2) to compensate patients injured as a consequence of the negligence of the hospital, physician, or ancillary health care

* Professor of Sociology and Director, Center for Medical Sociology and Health Services Research, University of Wisconsin-Madison.

The author appreciates the helpful comments of Lawrence Friedman in the preparation of this Article.

THE FOLLOWING CITATION WILL BE USED IN THIS ARTICLE:

U.S. DEP'T OF HEALTH, EDUCATION AND WELFARE, REPORT OF tHE SECRETaRY's Commission on Medical Malpractice (1973) [hereinafter cited as Medical MaIPRACTICE REPORT].

1. See N.Y. Times, Jan. 8, 1974, at 1, col. 6; id., June 1, 1975, at 1 , col. 1 ; cf. J. O'CONNELl, ENDING INSULT TO INJURY: NO-FAULT INSURANCE FOR PRODUCTS AND SERVICES 41-42 (1975).

2. See Medical Malpractice Report 18.

3. J. O'Connell, supra note 1, at 42-44; Brown, Social Resource Allocation Through Medical Malpractice, 6 WiLlaMeTTE I.J. 235, 242 (1970). 
personnel. ${ }^{4}$ As to the first function, it is assumed that the threat of possible malpractice litigation encourages prudent behavior beyond that which is learned in the training of the health professional. Particularly in the case of the hospital, such a threat is believed to result in greater attention to risks with low probability (such as those due to imadequate safety precautions, the unavailability of specialized equipment which is needed infrequently, or madequate supervision of personnel). It is not clear what proportion of malpractice claims or dollars awarded is related to such problems, ${ }^{5}$ but it is assumed that since hospitals are rated by risk, there is an incentive operating to avoid malpractice claims. ${ }^{\circ}$

Although physicians are not usually rated by risk beyond the nature of their specialized fields, it is assumed that the stigma associated with a malpractice judgment is a significant deterrent to carelessness. It is not obvious, however, that physicians perceive malpractice claims as stigmatizing, and it appears that some feel merely harassed and persecuted by the claims. Some very fragmentary and inadequate data suggest that physicians may have syinpathy for a colleague who is sued, and may refer patients to such a colleague to ensure that he does not suffer financially from malpractice litigation. ${ }^{7}$ Perhaps the most troublesome aspect of having a malpractice claim made against a physician is the anxiety, lost time, and uncertainty that may be involved. Even when such claims are rejected, and physicians vindicated, being sued is an unpleasant and disruptive experience. Thus, the costs to the physician must be weighed not only in terms of the awards actually made, but in terms of the total costs of becoming entangled in sucl an mcident. A claim made against a conscientious physician may cause him considerable suffering and may distract him from his best efforts.

The second generally accepted function of the malpractice mechanism is to conipensate persons who suffer imjury as a result of errors in treatment. But nedical malpractice suits are at best a capricious and inequitable means of compensation. While sonie claimants obtain very large awards, others suffering from equally serious injuries receive no conipensation at all. If our social insurance system were more satisfactory, and provided ample coinpensation for necessary

4. Brooke, Medical Malpractice: A Socio-Economic Problem From a Doctor's View, 6 WILLAMETTE L.J. 225, 226 (1970).

5. Medical Malpractice Report 5-12.

6. Id. at 41-42.

7. Schwartz \& Skolnick, Two Studies of Legal Stigma, 10 Social Prob. 133, 138-39 (1962). 
medical costs and for disability resulting in dependence, the malpractice issue would be a less important concern for us. Although there would still be a need to deal with compensation for pain and suffering resulting from negligence, this is probably the aspect of malpractice laving the least social significance. Because we do not lave an adequate system of health care insurance, and because assistance for the disabled and dependent is modest, the manner in which the medical malpractice mechanism compensates victims of neghigence looms more significant.

\section{Hypotheses Concerning the Growth of Medical Malpractice Litigation}

In recent decades medical science and technology have experienced dramatic growth, accompanied by increasing specialization and subspecialization of medical care and a larger and more heterogeneous mix of lealth care manpower. ${ }^{8}$ Public expectations concerning the performance of the medical sector have also grown, stimulated by the mass media's treatment of impressive developments in medical technology and knowledge. All of these changes-as I shall attempt to illustrate-contribute both to the probability that errors will occur and to the probability that patients, becoming cognizant of errors, will make claims against physicians.

Increasimgly, plysicians have available a more powerful technology for evaluating and treating disease, but a technology that also can cause havoc when incorrectly applied. The traditional practitioner, with liis little black bag, was able to affect disease in only a modest way, but his possibilities of doing harm were also more limited than at present. Given the complex technology that plysicians now command, luman error having important adverse consequences is inevitable even when physicians are fully qualified, careful, and prudent. More important is the fact that, unlike the errors of his predecessors, the errors of a modern plysician liave great capability for harm. Even a small lapse in judgment or attention in the application of a complex and risky treatment or diagnostic procedure may have major consequences for the patient in terms of pain experienced or resultant disability. While we all might agree that in the use of highrisk procedures (such as heart catheterization or particular types of biopsies) a certain probability of adverse events is to be expected, the physician has no assurance that a malpractice claim will not be made

8. See generally H. Greenfield, Alitidd Health MaNpower: Trends and PROSPECTS (1969). 
against him when such adverse consequences occur, nor that a finding of fault will not result.

The uncertainty experienced by the physician results, in part, from the ambiguity of medical standards and the unknown criteria for a finding of malpractice. The occurrence of adverse events varies a great deal among physicians and hospitals, and depends both on the quality of the professionals and on the types of cases imvolved; it has been demonstrated repeatedly that teaching hospitals in general provide higher quality care than proprietary hospitals. ${ }^{9}$ The fact that variations in performance exist does not imply that those with poorer performance are guilty of malpractice; yet it remains unclear what standard of medical practice will be perceived by judge or jury as below the acceptable minimum. The determination is arrived at through the process of an adversary proceeding in which claimant and defendant marshal various evidence to sustain their positions. Given the nature of this process, it is quite possible that adverse effects, which may be reasonably anticipated in at least some cases where complex diseases are treated with dangerous medical techniques, may be seen by juries as instances of malpractice.

The problem is made especially difficult in that the existence of a given probability of adverse events does not mean that when such events occur they are not a result of errors. For exainple, we can predict quite reliably the approximate deaths and ijjuries due to automobile accidents in the coming month. We know, given our system of highways, the construction of automobiles, human error in driving, variable weather conditions, and the like, that in the aggregate a certain rate of accidents is mevitable. This does not mean that in any particular accident we calmot specify that the proximate cause of the imjury was the error of one of the parties involved. Similarly, while statistically it may be inevitable that a gastroenterologist, in inserting gastroscopes in thousands of patients' stomachs, will pierce the wall of an individual's stomach, in any mstance in which the stomach is injured it may be due to momentary negligence or an error of judgment on the part of the physician. While we recognize that there are errors in all human activities, and thus it is unjust to stigmatize the physician in such cases, it still may be fair to compensate the injured patient.

An element in the apparent increase in malpractice awards is the unwillingness of hospitals, physicians, and insurers to contest small

9. Goss, Organizational Goals and Quality of Medical Care: Evidence from Comparative Research on Hospitals, 11 J. HeAlth \& SOCIAL BeHavior 255 (1970). 
claims, even when their merits are dubious, because of the costs of prolonged litigation. ${ }^{10}$ There is a tendency to agree to small settlements to avoid the harassments of litigation. It has been alleged that awareness of this among lawyers encourages litigation that would not have been pursued had defensive efforts been more persistent. In conjunction with certain other incentives for litigation, including the contingent fee and the absence of a requirement to pay costs in an unsuccessful suit, it is not surprising that malpractice litigation occurs inore commonly in the United States than in other countries where these incentives do not exist. ${ }^{11}$ Depending on one's perspective, lowever, the American system may be thought superior in providing poor litigants a fair opportumity to seek redress under circumstances in which they feel they have been injured. The inhibition of sucli litigation in miany countries may reflect too strong a bias in favor of the authority of the nuedical profession.

The emerging niedical organization that lias accontpanied growing medical knowledge and technology has also probably contributed to increased litigation. As a larger number of people are involved in a patient's care, the risks of errors in communication and follow-up treatment are very nuch increased. Similarly, the fragmentation of care leads to an erosion of the relationships between doctors and patients and of the quality of commumication and trust. ${ }^{12}$ Thus, misunderstandings between doctor and patient are more likely to occur, and patients are less likely to develop loyalty and commitment to a physician. When things go wrong they are niore likely to feel that he is blameworthy, and are more likely to consider litigation.

Evidence for this point of view is at best fragmentary. One study in California found that patients who sued doctors reported that the doctors had been unresponsive and had insisted on large payments despite adverse results. ${ }^{13}$ Some additional support comes from a study of consumer attitudes conducted by the Temple University Institute of Survey Research. ${ }^{14}$ In this national study involving

10. See Sagall, Medical Malpractice: Are the Doctors Right?, 10 TruaL 59 (July/Aug. 1974). But see Keeton, Compensation for Medical Accidents, 121 U. PA. L. REV. 590, 596 (1973).

11. See Addison \& Baylis, The Malpractice Problem in Great Britain, in Medrcal MALPRACTICE RePort Appendix 854; Welsh, Medical Malpractice in Canada, in Medical Malpractice Report Appendix 849.

12. See generally D. Mechanic, The Growth of Bureaucratic Medicine (1976).

13. R. Blum, The Management of the Doctor-Patient Relationship (1960); R. BLUM, THE PSYchology OF MALPRACTICE SUITS (1957).

14. Peterson, Consumers' Knowledge of and Attitudes Toward Medical Malpractice, in Medical Malpractice Report Appendix 658. 
1,017 interviews, the surveyors found that while respondents had favorable attitudes toward the technical competence of physicians, inost people felt that relationships with doctors had deteriorated over the last twenty years. ${ }^{15}$ A subgroup of respondents reported that either they or nembers of their families had suffered a negative medical care experience. Persons reporting such negative experiences were more likely to report also that today's doctors inaintained poor doctor-patient relationships. ${ }^{16}$ Major reasons given for the view that physicians have become less dedicated were that they are too interested in money, that they are less accommodating and more difficult to reach, and that they are more impersonal or inconsiderate. ${ }^{17} \mathrm{Al}-$ though it is impossible to infer causal relationships from correlational findings, these data are at least consistent with the hypothesis that deteriorating and impersonal doctor-patient relationships contribute to the malpractice problem.

Still another factor in the rise of litigation is the changing character of both the medical and legal communities. Until relatively recently it was difficult to litigate a malpractice case successfully because of the unavailability of medical testimony. ${ }^{18}$ Increasingly, Anerican medicine has become more fragmented, and medical testimony is more accessible to patients and their attorneys. ${ }^{19}$ Physicians now more commonly concede that they have a responsibility to testify for a patient who they believe lias been wronged. Similarly, it appears that lawyers are more willing to accept malpractice work, and firms have emerged that specialize in this area. ${ }^{20}$ It lias been alleged that receptivity annong lawyers to malpractice litigation increased following the implementation of no-fault automobile insurance. Any serious test of that allegation would require a comparison of data obtained over time from states with and without no-fault automobile insurance. It seems nore likely that growing litigation in the medical area is a result of a variety of factors, mcluding the increased availability of inedical testimony. Lawyers tend not to accept malpractice work unless medical corroboration is available. ${ }^{21}$ Finally, all of these

15. Id.

16. Id. at 678 .

17. Id. at 668 .

18. 3 A. Auerbach, Handling Accident Cases 9-10 (1960); M. Gross, The Doctors 520 (1966).

19. Medical Malpractice Report 36-37.

20. See, e.g., Waxman, A Health Care Slide, 11 Trial 24 (May/June 1975). See generally Frankel, Medico-Legal Communications, 6 WILLAMETTE L.J. 193, 218 (1970).

21. Dietz, Baird \& Berul, The Medical Malpractice Legal System, in MEdical MALPRACTICE REPort Appendix 99. 
changes are concurrent with growing sophistication among consumers, increasing acceptance of consumer rights, and greater accessibility to legal services.

There is little question that the growth of medical technology and its dramatic achievements have done a great deal to increase popular expectations of the possibilities of medical treatment. People often expect miracles, but they are less tolerant of the dangers associated with the use of new techniques. Evidence from other areas of medical care research suggests that when patients have unrealistic expectations about their medical treatment, they feel more angry and dissatisfied with their care and pose more difficult problems of inedical management and social adjustment. ${ }^{22}$ It seems reasonable to extrapolate from such studies the principle that public expectations- to the extent they are unrealistic-contribute to growing disappointment in experience and to greater expressions of dissatisfaction, thus contributing to malpractice litigation.

Perhaps most basic-but also more vague-is a growing sense of distrust in conteinporary American society. Trust is the glue that cements human relationships, that allows us to proceed-though inadequately informed-with some confidence that the claims made by others are reliable. We live im a period in which all claims are increasingly scrutinized, and it is nore common to see the motives and sincerity of people challenged. With the increasing coinplexity of technology and social organization, there is an enormous proliferation of rules, regulations, and contracts that help to define rights and obligations. Yet even in the most bureaucratic context, written rules are but a sinall fraction of the necessary understandings required to carry out activities. Flexibility and discretion are necessary for effective performance, and these must depend to some extent on trust. As trust becomes more unstable, efforts are made to formulate inore and more rules to govern behavior, but the proliferation of rules, and the difficulty of writing them in a way that will achieve the desired ends, result in imefficiencies and tendencies toward mampulation. In short, when the level of distrust becomes too high, social institutions are threatened, and an atteinpt to impose further rules and regulations will prove an inadequate remedy.

It is difficult to assess to what extent current malpractice difficulties reflect growing distrust of physicians. Certainly, available evi-

22. See I. Janis, Psychological Stress (1958). See also Egbert, Battit, Welch, et al., Reduction of Postoperative Pain by Encouragement and Instruction of Patients, 270 New ENG. J. Med. 825 (1964). 
dence continues to support the assertion that physicians are highly regarded by the public and continue to occupy a privileged status among American occupations. ${ }^{23}$ But the medical profession in recent years has been subjected to a barrage of criticisms, both from outside and from within, that has contributed to some loss of trust and confidence. With unfavorable mortality and morbidity statistics, misuse of human subjects in experimentation, dominance and control in the profession's self-interest, and profiteering and chicanery on the part of a few physicians in public programs, the public has been given considerable basis for insecurity. And this has occurred at the same time that the public has become, in some sense, inore dependent on medical care for general social sustenance due to the erosion of other social institutions such as the church, the kinship group, the neighborhood, and the family. The public seems to sliare a strange ambivalence about medical care-characterized by ligh and often unreasonable expectations, a strong sense of dependency, and a critical attitude. It is precisely when people expect too much that they are most likely to suffer bitter disappointunent.

None of the foregoing should be taken to mean that inedicineand the way it is practiced-has made no contribution to the growing sense of dissatisfaction. Certainly there have been abuses, and the thrust of medical organization lias not been toward the preservation of close doctor-patient relationships, educational dialogues between practitioners and patients, or the humanization of medical services. While physicians are often kind and lielpful, their priority has been the absorption of new technologies and their efficient application, and not medical practice as a broader social endeavor. But even if their priorities lad been different, it is not clear that the problems we now face could have been avoided. The malpractice crisis, in part, reflects the larger society of which it is a part, and it may be that there is only a limited amount that physicians can do to alleviate it.

\section{The Epidemiology of Medical Malpractice Litigation}

Although it is difficult to locate current data on the occurrence of malpractice claims, the estimates from the Secretary's Commission on Medical Malpractice will serve our purposes. Patients tend to be naive about the possibilities and dangers of medical treatment, and lack any clear standard by which to decide whether the physician behaved negligently. Thus patients may use a variety of standards such

23. A. Reiss, JR., Occupations and Soctal Status (1961). 
as bad outcome, apparent irregularities in the physician's behavior, or advice of friends or relatives as clues to the possibility that they have suffered a wrong. Desire to take some action against a physician may result as much from superficial clues, which the patient associates with a bad outcome, as from any objective medical circumstance. Or, conceivably, the motivation for a complaint may result as much from a desire for retribution for what the patient feels is callous and inhumane behavior on the part of the physician as from any seriously negative outcome. We know too hittle about how medical encounters that are eventually hitigated compare with ordinary medical encounters.

Once a patient has come to believe that negligent beliavior has occurred, he is likely to make inquiries, discussing his experiences with relatives and friends. If he is to make a claim he must find a lawyer willing to pursue the case, and this too will depend on whether he finds an appropriate legal pathway. He may be discouraged by his initial contact with a lawyer who is uninterested in sucl a case or views the grievance as either inappropriate or unprofitable to pursue. The ability to make successful contact with a suitable lawyer probably depends both on the patient's sophistication and social network and on the characteristics of the bar in the region in which he lives.

On the basis of data from twenty-six of the largest malpractice insurance carriers, the staff of the Commission on Medical Malpractice estimated that a malpractice imcident was reported or alleged by physician or patient for one of every 158,000 patient visits. ${ }^{24}$ A claim was made for one of every 226,000 visits. ${ }^{25}$ Only one in ten claims ever reached trial, and one half of the payments made in response to claims in 1970 were for less than $\$ 2,000 .{ }^{26}$ Although the dollar amounts have escalated somewhat in the past few years, the basic point still holds true that the vast majority of awards are relatively small.

A contentious issue is whether too many malpractice suits are being filed. Many physicians feel that litigation is often mischievous and unduly encouraged by a variety of incentives that are not present in other countries. ${ }^{27}$ Among the procedures often discouraged else-

24. Medical Malpractice Report 12. See also Rudov, Myers \& Mirabella, Medical Malpractice Insurance Claims Files Closed in 1970, in MEDICAL MALPRACTICE REPORT Appendix 1.

25. Medical Malpractice Report 12.

26. Rudov, Myers \& Mirabella, supra note 24, at Appendix 21.

27. See N.Y. Times, June 2, 1975, at 53, col. 4; J. O'CoNnelr, supra note 1, at 39. 
where are the contingent fee, the doctrine of res ipsa loquitur, the use of juries, and the absence of the requirement that the loser pay the winner's litigation costs. ${ }^{28}$ It is important to recognize, however, that the United States differ's in fundamental ways from some of the other countries with which it is compared. American culture encourages an attitude less acceptant of authority, and more willing to cliallenge it, than almost any other country in the world. We also have a very heterogeneous population, a wide variety of alternative value systems and life styles, and extremely effective national systems of communication. The population is highly mobile geographically, and people's ties with neighborhoods and communities are weak. Moreover, American medicine is more complex, inore heterogeneous, more technologically developed, and more uneven in quality than that of most comparably developed nations. Americans are also more likely to have high expectations of their medical care, and probably have better access to lawyers. Thus, regardless of incentives for litigation inherent in the legal system, the conditions exist, particularly in urbanized areas, for a demanding and aggressive stance toward the medical care system. In England, and perhaps in other countries, patients are more docile and more accepting of whatever care they are given. ${ }^{29}$

If we had an adequate defimition of "fault," we could determine through investigation those cases in which injury resulted from negligence, and compare them with malpractice claims filed and awards actually made. In the absence of such data sonie indirect indication of whether too many claims are being niade can be obtamed through surveys of lawyers and patients. The national Malpractice Commission surveyed lawyers who reported that they accepted approximately one in eight claims among chents alleging malpractice. ${ }^{30}$ About half of the claims rejected by the lawyers were attributed to a lack of liability. Before lawyers accepted a malpractice case they usually required evidence that there was a reasonable possibility of malpractice, corroborated by a physician's opinion. Attorneys reported that malpractice claims took more time to litigate than other negligence work, and felt that they were turning down worthy claims because the stakes were too small in relation to the required work.

The Temple University survey, referred to earlier, provides some data from a consumer perspective. About two fifths of the 1,017

28. See Addison \& Baylis, supra note 11, at Appendix 860; Welsh, supra note 11, at Appendix 851-53.

29. See Mechanic, General Medical Practice in England and Wales: Its Organization and Future, 279 New ENG. J. Med. 680 (1968).

30. Dietz, Baird \& Berul, supra note 21, at Appendix 99-101. 
respondents reported that either they, their spouses, or their dependents had suffered negative medical care experience within the past ten years. $^{31}$ Such reports, of course, reflect only the perceptions of the respondents, and provide no imdication of the degree of malpractice involved. But it is interesting that only thirty-seven respondents, or eight percent of respondents reporting adverse experiences, indicated that legal advice was considered. ${ }^{32}$ Only fourteen respondents took the matter up with a legal adviser, and six made a claim of malpractice. Of these, two later withdrew the claim without settlement, two settled before trial, and two claims were still in process at the time of the study. ${ }^{33}$ Thus it appears that very few of the grievances experienced lead to claims of negligence.

These two studies provide some indirect indication that the number of claims made against physicians is not excessive, given the extent to which patients perceive grievances and the extent to which lawyers feel that claims of neghigence have some merit. Moreover, physicians working in the area of quality assurance have reported that serious errors occur frequently and that a large proportion of hospital records show nnajor errors of omission or commission. ${ }^{34}$ While only some of these errors may result in serious adverse consequences for the patient, any of then potentially can become an issue in a malpractice suit. Lawyers apparently feel that too inuch work is involved in pursumg small claims, and in any case the costs of imitiating hitigation would leave hitigants with very little compensation. Indeed, one of the major problems with the existing inalpractice mechanism is the very high administrative costs and the modest compensation left for the litigant. ${ }^{35}$ A countervailing tendency, as suggested earlier, may be the willingness of defendants to settle small suits quickly to avoid their nuisance value, thus encouraging such claims. But it is likely that the deterrent against small claims is the more powerful one.

\section{The Problem of Defensive Medicine}

One of the most confused areas involved in the malpractice discussion concerns the allegations of defensive medicine. Physicians

31. Peterson, supra note 14, at Appendix 668-75.

32. Id. at Appendix 674-75.

33. Id. at Appendix 675.

34. Medical Malpractice Report 10.

35. Id. at 34; Medical Malpractice: A Discussion of Alternative CompensaTION AND Quality Control Systems 17 (D. McDonald ed., Center for the Study of Dem. Inst., 1971). 
have been vocal in their claims that the current inalpractice situation encourages them to engage in protective maneuvers that are expensive but have relatively little value. ${ }^{36}$ Some state that the growing litigation induces them to use expensive, and sometimes risky, diagnostic procedures to provide a record protecting thein against liability, should their behavior be at issue. To the extent that this occurs, it unnecessarily inflates the costs of medical care. Other physicians claim that the threat of litigation forces them into a defensive posture when performing certain procedures or treating certain types of injuries associated with high rates of litigation. In neither case is there much hard evidence that defensive medicine significantly distorts the process of medical care.

Professor Hershey ${ }^{37}$ has tried to narrow the issue by defining defensive medicine as a "deviation from what the physician believes is sound practice and which is generally so regarded, induced by a threat of liability."38 The key phrase here is "generally so regarded," the content of which is difficult to define. The core of the difficulty in making sense of defensive medicine is the looseness and ambiguity of medical standards. Presumably, defensive medicme occurs because physicians feel that they are vulnerable to charges of neghigence when they fail to perform certain "unnecessary" tests or procedures such as a skull $x$-ray following head trauma. Physicians would be vulnerable if they did not use such procedures because other physicians, competent in their specialty, inay testify in malpractice cases that the performance of such procedures is essential for an appropriate assessment of the patient's injury. Since physicians find it difficult to agree about many aspects of diagnosis and treatment, the physician who wishes to follow a less elaborate course of evaluation and treatment may feel that he becomes vuhierable in the event of a claim against him. Allegedly, this leads to the use of unnecessary procedures.

The purpose of standards is to bring the practice of each physician to a mininal norm of acceptable practice. To the extent that a standard is established when there is considerable disagreement, the standard induces persons to practice differently from the way they would in its absence. For those who agree with the standard, it is seen as

36. Medical Malpractice Rerort 14; Project, The Medical Malpractice Threat: A Study of Defensive Medicine, 1971 Duke I.J. 939, 942; cf. Ribicoff, Medical Malpractice: The Patient Versus the Physician, 6 Truat 10-27 (Feb./Mar. 1970) (discussing the phenomenon of "negative" defensive medicine).

37. Hershey, The Defensive Practice of Medicine, Myth or Reality, 50 MmBank MeMORIAL FUND Q. 69 (1972).

38. $I d$. at 72 . 
a definition of appropriate care; for those who see the standard as unrealistically high, conformity constitutes defensive medicine. In short, arguments about defensive inedicine inevitably reflect disagreements and confusion about the practice of inedicine itself.

If defensive medicine were as great a problem as many physicians allege, one might expect certain regional variations in practice. For example, one would suppose that in states or localities with high rates of litigation, physicians in particular specialties would be much more likely to use certain procedures in dealing with problennatic cases than would comparable physicians in low-hitigation areas. Although there are no large-scale studies of the question, one attempt to examine this hypothesis found little evidence in its support, and suggested that varying patterns of physician behavior are more likely to reflect local norms and professional customs than the threat of litigation. ${ }^{39} \mathrm{Al}-$ though it is no doubt true that some physicians order tests and procedures which they feel are unnecessary due to their fear that a lack of such testing may lead to liability, the fact may be that these tests and procedures should be done. The real issue is one of standards, and in this area medicine is in a muddle. As a result, there are some crucial issues of defensive medicine, but they are different from the examples physicians usually cite.

Most of what is regarded as acceptable cominunity practice is based on judgments of medical process and not of outcome. Up to now physicians have been trained in and have practiced within the philosophy that Victor Fuchs has called the "technologic imperative," ${ }^{\prime 0}$ nainely, to the extent that a procedure can possibly be helpful to the patient, it should be done. These judgments are made without serious consideration of their cost-effectiveness. Thus, certain practices that are based entirely on process judgments have becoine normative, even in some cases where outcome studies raise serious questions about the value of the procedure. Such norms defining customary practice make it very difficult for a physician to act solely on the basis of the research literature when this literature is not consistent with custom.

Take, for example, the proliferation of intensive coronary care units. While many physicians beheve such units to be of value in saving lives, controlled trials fail to support this belief, at least for nany

39. Project, supra note 36 , at 959-60.

40. Fuchs, The Growing Demand for Medical Care, 279 New ENG. J. Med. 190 (1968). 
common cardiac incidents. ${ }^{41}$ But, given the climate of physician opinion and customary practice, a medical group would feel extremely vulnerable to malpractice claims if it departed from the use of coronary intensive care despite a belief that sucl care is unnecessary and expensive. Also, when there is division in the medical community concerning the value of a given procedure, a prudent physician is likely to lean toward doing too much, since physicians involved in a malpractice trial might be able to make a more convincing case to a jury that the procedure sliould liave been undertaken. Simce the outcome of a contest between adversaries is in doubt when the medical situation is unclear, the uncertainty is likely to reinforce the technologic imperative.

From a purely economic point of view, an important question about the existing malpractice mechanism is the extent to which it increases the total aggregate costs of medical practice by reinforcing conservative decisions. As resources for medical care become more limited relative to the increasing technological possibilities, medical planners will have to develop means to establish priorities and to determine which procedures truly enhance outcome. Whether they will do so through government-promulgated standards, through local standards developed by Professional Standards Review Organizations (PSROs) or peer review groups, through consumer participation and mput, or some combimation of all three, is not clear. ${ }^{42}$ What is required, however, is a meclianism for legitimizing the standards adopted so that professionals who conforn to thein can feel relatively safe from negligence claims. Such standards, however, should also reflect cost-effective practice so that they do not further reinforce the technologic miperative and the trend of imcreased medical care costs.

\section{The Distributive Effects of Malpractice Litigation: Who Bears the Risk?}

The existing malpractice mechanism is an inequitable way of compensating persons who suffer adverse consequences as a result of neghigence. It is inequitable because the awareness of medical error,

41. Mather, Pearson, Read, et al., Acute Myocardial Infarction: Home and Hospital Treatment, 3 BRrt. Med. J. 334 (1971). See also A. CochraNe, EFFectiveness aNd Efficiency: Random Reflections on Health SeRvices (1972).

42. One recent Note suggests that the due process clause requires that extensive procedural safeguards be used in making any decision concerning allocation of scarce medical resources. Note, Due Process in the Allocation of Scarce Lifesaving Medical Resources, 84 YALE L.J. 1734 (1975). The procedural implications of such a position, if accepted by the courts, would be considerable. 
the process of making a claim, and the amount of compensation paid are not congruent with the adversities suffered by patients due to negligence. Compensation tends to be much influenced by a variety of social, psychological, and personal factors. Moreover, the true costs involved in bringing and contesting claims are substantial, and only a modest proportion of the inoney awarded constitutes actual compensation to the litigant. While no-fault insurance has been advocated for the inedical care area, such a proposal leaves unsolved the difficult problem of distinguishing adverse outcomes resulting from negligence from those that are the product of the natural development of the patient's condition or that result unavoidably from high-risk therapy. Many medical measures are dangerous, but are used to forestall even greater adverse consequences related to an illness. Under the existing tort system the adversary process reaches the necessary decisions as to which incidents can be said to flow from physician error as opposed to other causes. Under a no-fault system, other fact-finding and decision-making techniques would be necessary.

While this paper does not deal with alternatives to malpractice, such as arbitration or mediation, it is relevant to consider some underlying questions concerning alternative decision-making devices. Many physicians, alarmed by increasing malpractice rates, advocate no-fault insurance in the hope that sucli a mechanism would be less expensive than the present system. ${ }^{43}$ While it certainly seems plausible that a no-fault systein would substantially reduce the middle-man costs associated with extensive hitigation, it does not follow that an effective no-fault system would be less expensive; indeed, it may be far more costly. Unless the administration of such a system were quite conservative, it might require that many more patients be compensated.

First, a no-fault system may generate more claims simce the inhibition against charging one's doctor with personal negligence may be relieved by the no-fault definition. Second, it is conceivable that under a no-fault system, physicians may be more willing to inform patients that they have been injured as a result of medical treatment, and encourage them to seek compensation. Third, a no-fault system might foster a moral obligation on the part of the medical care system to compensate injured patients even when these patients liave not become aware of the cause of their problems or have failed to make a claim because of ignorance, timidity, passivity, or whatever. Such

43. N.Y. Times, Feb. 8, 1974, at 12, col. 1. But see J. O'ConNeLL, supra note 1, at 73-74 (discussing unexpected costliness of no-fault medical coverage). 
an approach would be far more equitable than simply compensating patients who are aggressive enough to pursue their claims; however, it would also be very expensive.

The class of adverse events most difficult to deal with under a no-fault system is that involving the use of high-risk techniques. A certain degree of error, as noted earlier in this Article, is inevitable, particularly in the use of complex inedical procedures. Some have argued that patients must assume such risks since they are an inevitable part of the treatment process. But the patient may be in the poorest position to assume the risk of inevitable medical errors. As a result of such errors the patient may suffer serious imjury, prolonged disability, and increased costs of medical care and dependence. It would be reasonable to share the risks of such costs with others using the same medical care system, but who luckily escape the inevitable error. If a procedure results in one adverse event in a thousand, the person who suffers that event is left with the total cost of the error. It would seem fairer to distribute the cost among the patients who benefit from the procedure. Though this would be a heavy burden for a system replacing malpractice, it would not be an unreasonable one. Many of the cosis could be assumed by increased health insurance coverage and disability compensation.

A no-fault system would protect unedical personnel and institutions against allegations that the inevitable errors result from their negligence and incompetence. We do not know whether the existing fault inechanism has a deterrent effect, but to the extent that it does, a no-fault system might neutralize it. On the basis of the data that I have studied on physician behavior, I am somewhat skeptical of the theory that the threat of malpractice actions has a inajor deterrent effect upon the technical work of physicians, although it nay well have a greater effect on the services that hospitals make available and on their supervisory procedures. But the interpersonal aspect of doctor-patient relationships is subtle, and unoving to a no-fault system may conceivably have inore important effects on such relationships than on technical performance.

In the traditional practice of fee-for-service medicine, the fact that the patient pays a fee gives him some modest influence in the relationship. As competition among doctors for patients declines, this influence is less potent, but the fact that a fee is involved affects the orientation of both patient and physician to some extent. ${ }^{44}$ Increas-

\footnotetext{
44. E. Fremson, Profession of Medicre: A Study of the Sociology of Applied KNOWLEDGE (1970).
} 
ingly, as patients have moved from fee-for-service to prepaid contexts they have suffered solne erosion of their influence unless they are particularly aggressive. In prepaid settings, physicians seem inore oriented to the standards of their colleagues than to the deinands of patients. ${ }^{45}$ Also, they are nnore likely to think of the typical patient as "trivial" in the prepaid situation and take him somewhat for granted. ${ }^{46}$ Similarly, patients in prepaid contexts are nore likely to complain about the physician's lack of interest in thein, his inflexibility, and the feeling that they are being treated like "charity cases." 47 This may be a reaction particularly associated with patients who grew up in a fee-for-service context and then changed to a prepaid plan, and it may be less of a problem for future generations who are more receptive to bureaucratic treatment. Increasingly, however, the patient has less leverage in his personal transactions with the physician.

One of the remaining sources of power for the patient is his ability to threaten or initiate malpractice litigation when he feels that his interests have been abused. Although patients rarely do so, the remote threat may to some extent control the bounds of physician behavior. The use of a malpractice threat as a means of stating a grievance may be a latent and undesirable aspect of the present system, but it may also be one of the last sources of the patient's power in his relationship with the physician, the clinic, or the hospital. Other means of increasing patients' involvement in their care have received a great deal of discussion, but few have been attempted on a major scale. ${ }^{48}$ Such tecliniques include complaint mechanisms, consumer participation in decision-making groups, regular opportunities for changing health programs (as in dual choice and re-enrollment), and the use of ombudsmen. While these are relatively uncertain substitutes for the power of the fee (and possibly also for the latent malpractice threat), they hold promise for the future.

The key poimt is that the malpractice problem is but a symptom of more basic problems in the organization and provision of health care and social services. An effective substitute for the existing system must be sensitive to the changing balance of power between

45. See N.Y. Times, Jan. 11, 1973, at 1, col. 1; id. at 22, col. 2.

46. Mechanic, Patient Behavior and the Organization of Medical Care, in INSTrTUTE of MEDiCINE, ETHICS OF HeAlTH (National Academy of Sciences 1973).

47. Tessler \& Mechanic, Consumer Satisfaction with Prepaid Group Practice: A Comparative Study, 16 J. Health \& Social Behavior 95 (1975).

48. See N.Y. Times, April 8, 1973, at 25, col. 1 (suggesting creation of federal agency to monitor quality of patient care under Medicaid and Medicare). 
patients and physicians, and must contain adequate channels for patients who feel wronged or harmed to state their grievances and to receive fair consideration. It is the development of such an alternative system that will require our long-term efforts. 